\title{
Acute Myelomonocytic Leukemia Presenting as Polyarthritis in Elderly
}

\author{
Robin George Manappallil ${ }^{1}$, Durga Prasan ${ }^{2}$, Neena Mampilly ${ }^{3}$, Ashish Pappinisseri Krishnan ${ }^{1}$ \\ Departments of ${ }^{1}$ Internal Medicine, ${ }^{2}$ Medical Oncology, ${ }^{3}$ Pathology, Baby Memorial Hospital, Calicut, Kerala, India.
}

\section{Corresponding Author:}

Dr. Robin George Manappallil

Email: drrobingeorgempl@gmail.com

This is an Open Access article distributed under the terms of the Creative Commons Attribution License (creativecommons.org/ licenses/by/3.0).

Received Accepted

Published
March 12, 2019

May 17, 2019

June 10,2019

\begin{abstract}
Background: Leukemic arthritis is commonly seen in children; and can mimic rheumatoid arthritis. The condition is usually pauciarticular involving large joints, but may also present as polyarthritis. Case Report: The patient being reported is an elderly male who presented with polyarthritis and fatigue, and was found to have acute myelomonocytic leukemia. Conclusion: Though arthritis is a common complication of leukemia in children, it may also occur in adults. The presentation is usually before the onset or during the course of disease. However, arthritis as an initial manifestation of leukemia is a rare scenario.
\end{abstract}

Keywords: Acute Myelomonocytic Leukemia, Arthritis, Bone Marrow, Joint Diseases.

\section{Introduction}

Bone and joint symptoms are common among leukemic patients [1]. Leukemic arthritis refers to joint pain and swelling in association with peripheral blood or bone marrow leukemia, provided other causes of arthritis have been excluded [2]. It can occur at any time during the course of the disease but arthritis as an initial manifestation of leukemia is rare [3].

\section{Case Report}

A 65 year old male presented to Medicine department with complaints of multiple joint pains of two months duration, along with progressive fatigue and dyspnea on exertion since last one month. He was told to have rheumatoid arthritis and was on ayurvedic medications. On examination, his vitals were stable. Pallor was present. He had mild joint swelling of bilateral hands [Fig.1], wrist, knees and feet [Fig.2]. Knee joints had mild redness and tenderness [Fig.3]. Other systemic examinations were normal.
His complete blood count showed anemia $(7.1 \mathrm{~g} / \mathrm{dL})$, leucocytosis $(20,000$ cells/cu.mm with neutrophils $40 \%$, lymphocytes $52 \%$, monocytes $8 \%)$ and thrombocytopenia $(1,04,000$ cells/ cu.mm). Renal and liver functions, electrolytes, thyroid stimulating hormone and urine routine were normal. Peripheral smear showed microcytic hypochromic anemia with blast cells. Antinuclear antibody profile, rheumatoid factor and anti-cyclic citrullinated peptide were negative. X-ray of knee joints showed soft tissue swelling and joint effusion. Bone marrow evaluation revealed suppressed erythroid series, arrested myeloid maturation with blast cells $25 \%$, myeloid precursors $16 \%$, monocytoid cells and promonocytes 34\% [Fig.4]. Flow cytometry immunophenotyping analysis was positive for CD13, CD 14, CD34, CD38, CD45, CD 68, CD117, HLADR and cMPO; suggestive of acute myelomonocytic leukemia. AML panel for INV16 (p13q22)/ t(16;16)(p13;q22), PML-RARA, NPM1 gene mutation, FLT3-ITD, FLT3-TKD, BCR-ABL and AML ETO were negative. Serum calcium and uric acid levels were normal and Coomb's test was negative. Synovial fluid analysis showed presence of blast cells. 


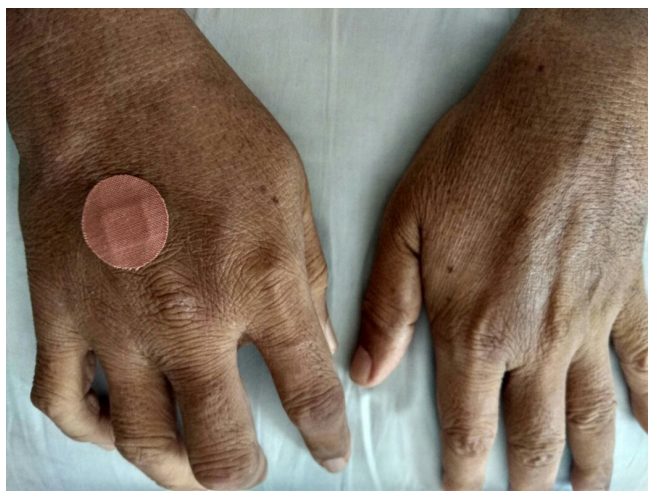

Fig.1: Arthritis of hands.

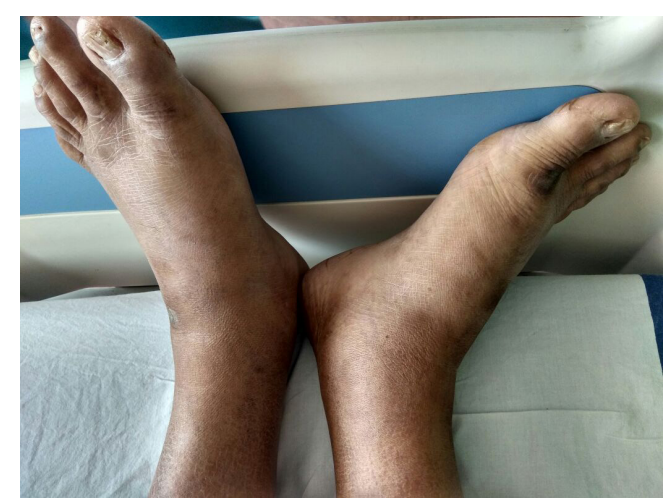

Fig.2: Arthritis of feet.

He was given packed cell transfusions along with intravenous deflazacort following which he showed symptomatic improvement. He was also started on tumor lysis prophylaxis (allopurinol $100 \mathrm{mg}$ thrice daily), antiviral (acyclovir $200 \mathrm{mg}$ four times daily), antifungal (fluconazole 150 mg once daily) and antibiotics (double strength cotrimoxazole twice daily). He was advised induction therapy with cytarabine/ daunorubin, but patient and his attendants wanted to try ayurvedic medications and hence was lost for follow-up.

\section{Discussion}

The myeloid leukemias are a group of heterogenous diseases characterized by infiltration of neoplastic cells of the hematopoietic system into the blood, bone marrow and other tissues. Leukemic arthritis is an uncommon manifestation of acute leukemia,

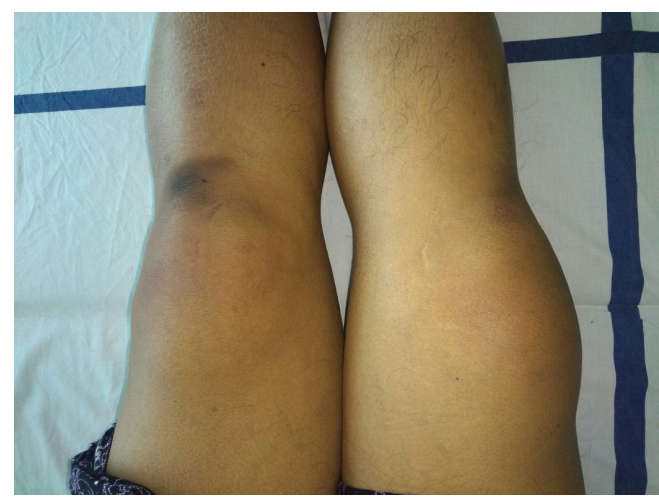

Fig.3: Arthritis of knee joints.

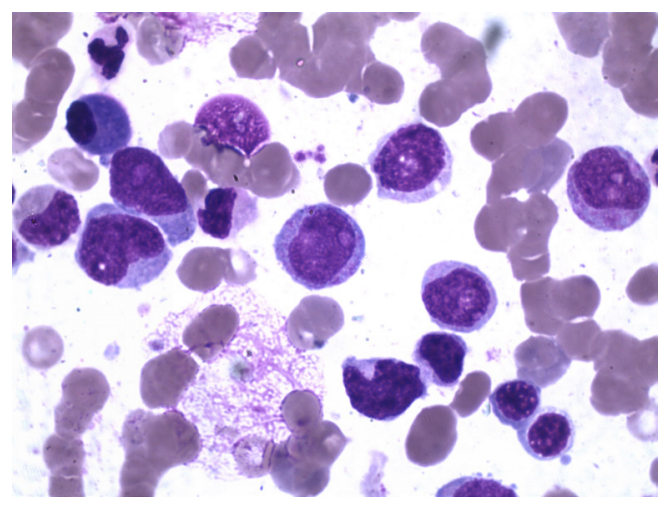

Fig.4: Bone marrow aspiration showing infiltration by leukaemic cells.

especially in adults. The condition is more common among children (12\% to $65 \%$ ) than adults (4\% to $13 \%$ ) and in cases of acute lymphocytic leukemia than acute myeloid leukemia $[4,5]$. The pathogenic mechanisms include infiltration of leukemic cells into the synovial tissue, hemorrhage into the joint space due to thrombocytopenia, synovial reaction to capsular or periosteal infiltration, and immune complex mediated synovitis $[6,7]$. The synovial tissue biopsy is unreliable due to patchy involvement of the synovium [8]. In some cases the synovial biopsy specimen may show no abnormalities $[9,10]$. Immunocytological or light microscopic examination of synovial fluid may also be useful $[11,12]$.

Arthritis usually occurs early in the course of acute leukaemia, as compared to chronic leukaemia. 
It is typically pauciarticular, but may also present as polyarthritis $[5,13]$. The large joints like knees are commonly affected. The involvement of joints like wrists, elbows, ankles, shoulders and hips have also been described. The affected joints are usually warm, tender and swollen. There is minimal joint effusion. The swelling is mainly due to synovial hypertrophy. Patients may or may not be febrile $[6,7,9]$.

Leukemic arthritis can mimic rheumatologic diseases, thereby making the diagnosis difficult. Investigations like peripheral blood smear and complete blood count can be non-specific. The diagnosis is usually made by examination of bone marrow aspirate or biopsy.

\section{Conclusion}

Arthritis is a known complication of leukemia in children, but may also occur in adults. The presentation is usually before the onset or during the course of disease. The diagnosis can be difficult as it can mimic rheumatologic diseases. Bone marrow aspiration and biopsy are required for the confirmation of leukemia. Synovial fluid analysis may also be useful. This case, therefore, highlights the importance of considering leukemia in case of arthritis. However, arthritis as an initial manifestation of leukemia is a rare scenario.

Contributors: RGM: concept and design of case report, reviewed the literature, manuscript preparation and treating physician; DP: critical revision of manuscript and treating oncologist; NM: critical revision of manuscript and pathologist; APK: patient management and manuscript revision. RGM will act as study guarantor. All authors approved the final version of this manuscript.

Funding: None; Competing interests: None stated.

\section{References}

1. Spilberg I, Meyer GJ. The arthritis of leukemia. Arthritis Rheum. 1972;15:630-635.

2. Luzar MJ, Sharma HM. Leukemia and arthritis: including reports on light, immunofluorescent and electron microscopy of the synovium. J Rheumatol. 1983;10:132-135.

3. Thomas LB, Forkner CE, Frei E. The skeletal lesions of acute leukemia. Cancer. 1961;14:608-621.

4. Fink CW. Arthritis as the presenting feature of childhood leukemia. Arthritis Rheum. 1972;15:347-349.

5. Evans TI, Nercessian BM, Sanders KM. Leukemic arthritis. Semin Arthritis Rheum. 1994;24(1):48-56.

6. Silverstein MN, Kelly P. Leukemia with osteoarticular symptoms and signs. Ann Intern Med. 1963;59:637-645.

7. Taillan B, Leyge JF. Knee arthritis revealing acute leukemia in a patient with rheumatoid arthritis. Clin Rheumatol. 1991;10:76-77.

8. Fort JG, Fernandez C, Jacobs SR, Abruzzo JL. B cell surface marker analysis of synovial fluid cells in a patient with monoarthritis and chronic lymphocytic leukemia. J Rheumatol. 1992;19(3):481-484.

9. Weinberger A, Schumacher HR, Schimmer BM, Myers AR, Brogadir SP. Arthritis in acute leukemia. Clinical and histopathological observations. Arch Intern Med. 1981;141(9):1183-1187.

10. Luzar MJ, Sharma HM. Leukemia and arthritis: including reports on light, immunofluorescent, and electron microscopy of the synovium. J Rheumatol. 1983;10(1):132-135.

11. Fam AG, Voorneveld C, Robinson JB, Sheridan BL. Synovial fluid immunocytology in the diagnosis of leukemic synovitis. J Rheumatol. 1991;18(2):293-296.

12. Yoon SS, Youn HD, Suh C, Bang YJ, Choi SJ, Kim BK, et al.Acase of leukemia-associated arthritis-identification of leukemic cells in synovial fluid by light microscopy. J Korean Med Sci. 1987;2(4):255-258.

13. Louthrenoo W, Kasitanon N, Sukitawut W. Arthritis in leukemia. J Clin Rheumatol. 2000;6(6):313-317. 